\title{
Microwave Absorption Properties of Double-Layer RADAR Absorbing Materials Based on Doped Barium Hexaferrite/TiO ${ }_{2} /$ Conducting Carbon Black
}

\author{
Sukanta Das, ${ }^{1}$ G. C. Nayak, ${ }^{1}$ S. K. Sahu, ${ }^{2}$ P. C. Routray, ${ }^{2}$ A. K. Roy, ${ }^{2}$ and H. Baskey ${ }^{3}$ \\ ${ }^{1}$ Department of Applied Chemistry, Indian School of Mines, Dhanbad 826004, India \\ ${ }^{2}$ Integrated Test Range (ITR), Chandipur 756025, India \\ ${ }^{3}$ DMSRDE, Kanpur 208013, India \\ Correspondence should be addressed to G. C. Nayak; ganeshnayak2006@gmail.com
}

Received 18 May 2014; Revised 14 August 2014; Accepted 7 September 2014; Published 17 September 2014

Academic Editor: Mariatti Jaafar

Copyright (C) 2014 Sukanta Das et al. This is an open access article distributed under the Creative Commons Attribution License, which permits unrestricted use, distribution, and reproduction in any medium, provided the original work is properly cited.

\begin{abstract}
In this report, we demonstrate microwave absorption properties of barium hexaferrite, doped barium hexaferrite, titanium dioxide and conducting carbon black based RADAR absorbing material for stealth application. Double-layer absorbers are prepared with a top layer consisting of $30 \%$ hexaferrite and $10 \%$ titanium dioxide while the bottom layer composed of $30 \%$ hexaferrite and $10 \%$ conducting carbon black, embedded in chloroprene matrix. The top and bottom layers are prepared as impedance matching layer and conducting layer, respectively, with a total thickness of $2 \mathrm{~mm}$. Microwave absorption properties of all the composites were analyzed in X-band region. Maximum reflection loss of $-32 \mathrm{~dB}$ at $10.64 \mathrm{GHz}$ was observed for barium hexaferrite based doublelayer absorber whereas for doped barium hexaferrite based absorber the reflection loss was found to be $-29.56 \mathrm{~dB}$ at $11.7 \mathrm{GHz}$. A consistence reflection loss value $(>-24 \mathrm{~dB})$ was observed for doped barium hexaferrite based RADAR absorbing materials within the entire bandwidth.
\end{abstract}

\section{Introduction}

In the recent years, X-band RADAR application increases in military sector due to its high precision target detection capability. Keeping it in view, microwave technology advancement is forced to focus on the development of efficient RADAR absorbing materials (RAMs) for applications in the field of stealth technology [1] and electromagnetic (EM) shielding. Therefore, there is a demand for effective microwave absorbing materials for wideband applications. RADAR wave in the form of EM energy can be completely or partially absorbed and dissipated into the absorbing materials through magnetic and dielectric losses. The phenomenon of the absorption is prominent if characteristic impedance of the free space is equal to the characteristic impedance of the absorber. Efficient RAMs can be prepared with materials which allows EM wave to penetrate easily and attenuate whole of the electromagnetic energy within itself [2]. Ferrites based RAMs show interesting behavior in $\mathrm{X}$-band frequency range and have been used in the form of sheets, films, paints, and ceramic tiles. Hexagonal barium hexaferrite and doped barium hexaferrite are suitable candidates to be used to develop composite RAMs due to their good permittivity and permeability value within X-band region. Gairola et al. [3] reported a maximum reflection loss of $-14.7 \mathrm{~dB}$ for $2 \mathrm{~mm}$ thick single-layered RAMs based on barium hexaferrite and $\mathrm{Co}, \mathrm{Mn}$, and Ti substituted barium hexaferrite. Qiu et al. [4] reported a nanocomposite multilayer absorber film using barium hexaferrite $\left(\mathrm{BaFe}_{12} \mathrm{O}_{19}\right)$ and titanium dioxide $\left(\mathrm{TiO}_{2}\right)$ with a maximum loss of $-40 \mathrm{~dB}$ due to the dielectric effect of titanium dioxide. Lopes et al. [5] studied microwave absorber based on nonwoven polyacrylonitrile fabric and conducting carbon black (CCB) and reported a reflection loss of $-22 \mathrm{~dB}$ in X-band region. However, all the reported electromagnetic absorber showed narrowband absorption which is a major drawback in RAMs development.

In this work Fe within barium hexaferrite was substituted with cobalt, titanium, and manganese, which helped in 
tailoring magnetic properties. Both barium hexaferrite and doped barium hexaferrite along with conducting carbon black (CCB) and titanium dioxide $\left(\mathrm{TiO}_{2}\right)$ were utilized to develop double-layer RADAR absorbing materials with wideband absorption capability.

\section{Experiments}

2.1. Preparation of Barium Hexaferrite (BaHF). A typical sintering method was followed for the synthesis of barium hexaferrite $\left(\mathrm{BaFe}_{12} \mathrm{O}_{19}\right)$ from barium carbonate $\left(\mathrm{BaCO}_{3}\right)$ and iron oxide $\left(\mathrm{Fe}_{2} \mathrm{O}_{3}\right)$ as reported by Gumaste et al. [6]. Both the compounds were mixed in a ball mill for 6 hours in stoichiometric ratio $(1: 6)$. The homogeneous mixture was then dried at $100^{\circ} \mathrm{C}$ for 24 hours to remove moisture. After that, calcination of the sample was carried out at $600^{\circ} \mathrm{C}$ for two hours and sintered at $1200^{\circ} \mathrm{C}$ for one hour. The powder sample was collected at room temperature for further characterization and processing.

\subsection{Preparation of Doped Barium Hexaferrite (CoTiMn-} $B a H F)$. Doped barium hexaferrite $\left(\mathrm{BaFe}_{10} \mathrm{Co}_{0.8} \mathrm{Ti}_{0.8} \mathrm{Mn}_{0.4}\right.$ $\mathrm{O}_{19}$ ) was prepared by "mixed oxide" approach as reported by Lima et al. [7]. In this synthesis process, substitution of $\mathrm{Fe}^{3+}$ sites was carried out, to make the materials magnetically soft in nature. All the individual components cobalt oxide $(\mathrm{CoO})$, titanium oxide $\left(\mathrm{TiO}_{2}\right)$, manganese oxide $(\mathrm{MnO})$, barium carbonate $\left(\mathrm{BaCO}_{3}\right)$, and iron oxide $\left(\mathrm{Fe}_{2} \mathrm{O}_{3}\right)$ were mixed together as their stoichiometric arrangements in a ball mill. Then the sample was dried by putting it into oven at $100^{\circ} \mathrm{C}$ for 24 hours. The powder sample was calcined at $600^{\circ} \mathrm{C}$ for 2 hours and sintered at $1200^{\circ} \mathrm{C}$ for 1 hour. The powder sample of doped barium hexaferrite was collected for further characterization and processing.

2.3. Preparation of Double-Layer RAMs. Two RAMs (RAMI and RAM-II) were prepared in chloroprene rubber (CR) matrix supplied by Dupont. BaHF based double-layer RAMs were made by two-step process. The composite RAMs were prepared by following the procedure reported by Peng et al. [8]. In the first step top layer of RAM-I was prepared by mixing $30 \%(w / w) ~ B a H F$ and $10 \%$ (w/w) $\mathrm{TiO}_{2}$ with $\mathrm{CR}$ matrix in an open two-roll mixture. The other processing additives added to the mixture were stearic acid ( $0.5 \mathrm{phr})$, CBS (0.6 phr), TMTD (0.2 phr), ZnO (3 phr), MgO (2 phr), and sulfur (1.5 phr). After completion of mixing, the material was pressed at room temperature by keeping it in a $1 \mathrm{~mm}$ thick mold to maintain its thickness. The $1 \mathrm{~mm}$ thick bottom layer was prepared by mixing $30 \%$ (w/w) $\mathrm{BaHF}$ and $10 \%$ (w/w) CCB with CR matrix in two-roll mixture along with other additives and pressed at room temperature to get $1 \mathrm{~mm}$ thick sheet. Now both the layers were placed into a $2 \mathrm{~mm}$ thick mold and the mold was kept in between two hot plates. Temperature of the hot plates increases up to $150^{\circ} \mathrm{C}$ and 2bar pressure applied for $15 \mathrm{~min}$. Then temperature of the mold reduced down to room temperature and double-layer RAMI was taken out of mold. RAM-II was prepared by using same methodology as RAM-I, and only BaHF was replaced by CoTiMn-BaHF.

\section{Characterizations}

The particle size and morphology of the BaHF, CoTiMn$\mathrm{BaHF}, \mathrm{CCB}$, and $\mathrm{TiO}_{2}$ were measured using field emission scanning electron microscope (FESEM) at an accelerating voltage of $5 \mathrm{kV}$. XRD was carried out for both BaHF and CoTiMn-BaHF using Rigaku Ultima III with cobalt source $(\lambda=1.78896 \AA)$. The complex permittivity and permeability of the composite RAMs were measured using an Agilent E8362B vector network analyzer (VNA) in the frequency range of $8-12 \mathrm{GHz}$. Reflection loss properties of the composite RAMs were measured using Agilent E8364B in the X-band frequency range $(8-12 \mathrm{GHz})$.

\section{Results and Discussion}

4.1. Morphological Study. FESEM images of BaHF, CoTiMn$\mathrm{BaHF}, \mathrm{CCB}$, and $\mathrm{TiO}_{2}$ samples are given in Figures 1(a)-1(d). It was observed that particle size of doped $\mathrm{BaHF}$ is smaller than undoped BaHF. Figure 1 (a) shows the BaHF particles with an average diameter of $500 \mathrm{~nm}$, whereas the average particle size of CoTiMn-BaHF was found to be $300 \mathrm{~nm}$. The CCB particles appeared to be spherical in nature and with an average diameter of $30 \mathrm{~nm}$ (Figure 1(c)). Figure 1(d) shows the microstructure of $\mathrm{TiO}_{2}$, which appeared as flakes.

4.2. X-Ray Diffraction. XRD diffractograms of BaHF and doped barium hexaferrite (CoTiMn-BaHF) are shown in Figure 2. Most of the peak patterns of CoTiMn-BaHF are the same as pure BaHF. The crystal planes are identified for both BaHF and CoTiMn-BaHF and indexed using JCPDS number 43-0002 ((101), (102), (006), (110), (107), (114), (203), (205), (206), (217), (2011), and (220)). The XRD pattern shows that $\mathrm{Mn}^{+2}, \mathrm{Co}^{+2}$, and $\mathrm{Ti}^{+4}$ ion were rearranged within the hexagonal magnetoplumbite structure to maintain the formation of single phase hexagonal ferrite entity. The average crystallite diameter (ACD) of the BaHF and CoTiMn-BaHF particles was measured as $42 \mathrm{~nm}$ and $32 \mathrm{~nm}$, from the major diffraction peak (114) using the well-known Scherrer formula. Due to substitution, it can be seen that peak height decreased, which can be attributed to the doaping effcet on crystallinity.

4.3. Magnetic Properties. A vibrating sample magnetometer (VSM) was used to measure the magnetic properties of $\mathrm{BaHF}$ and CoTiMn-BaHF. The resulting hysteresis loops provided the relationship between magnetization $(M)$ and applied field $(H)$ at room temperature. The parameters extracted from the hysteresis loops are saturation magnetization (Ms), remanence $(\mathrm{Mr})$, and coercivity $(\mathrm{Hc})$. Figure 3 shows the hysteresis loops for the BaHF and CoTiMn-BaHF. Because of high value of $\mathrm{Hc} 4194 \mathrm{Oe}$ for $\mathrm{BaHF}$, the material is a hard magnetic material [7]. From the plot, it can be seen that $\mathrm{Hc}$ value for CoTiMn-BaHF is 1496 Oe. Hysteresis loops show reduction in coercive force $(\mathrm{Hc})$ for CoTiMn$\mathrm{BaHF}$ classifying the material as soft magnetic material. The 


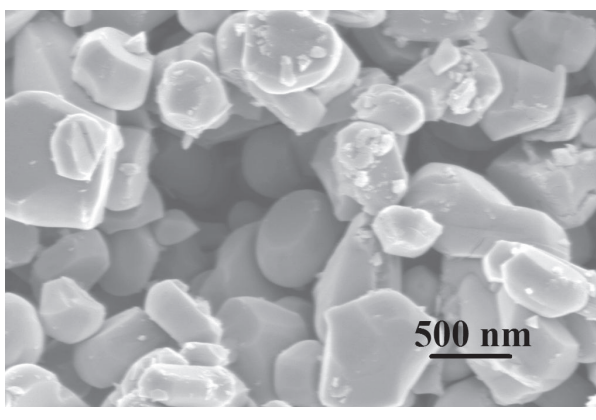

(a)

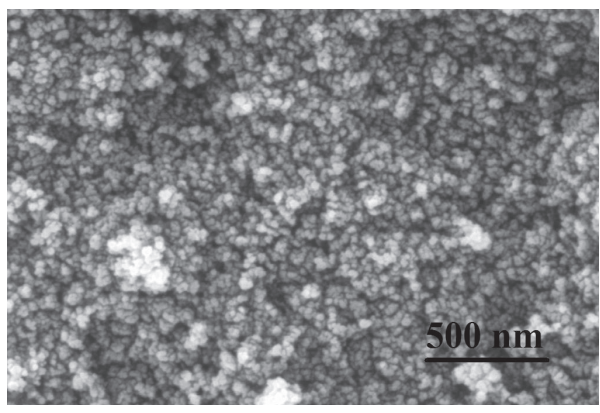

(c)

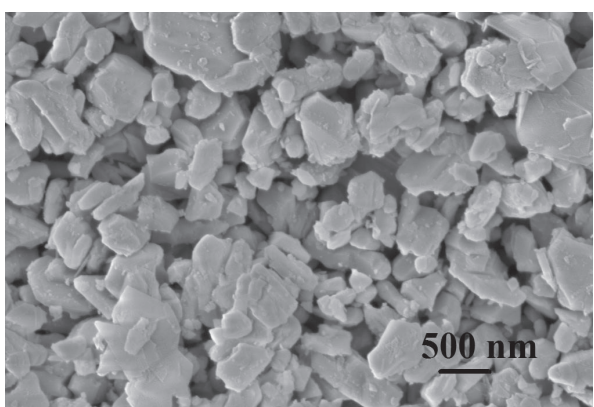

(b)

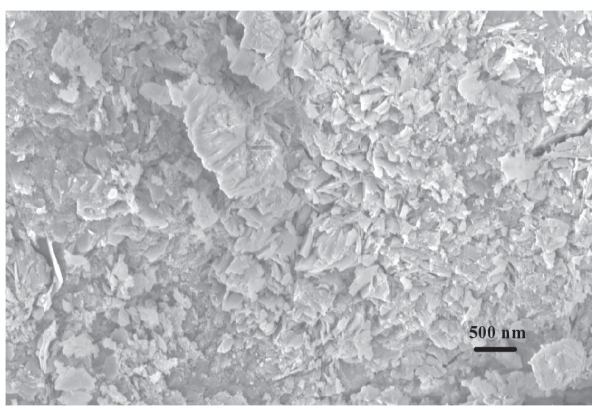

(d)

Figure 1: Surface morphology of (a) BaHF, (b) CoTiMn-BaHF, (c) CCB, and (d) $\mathrm{TiO}_{2}$ particles.

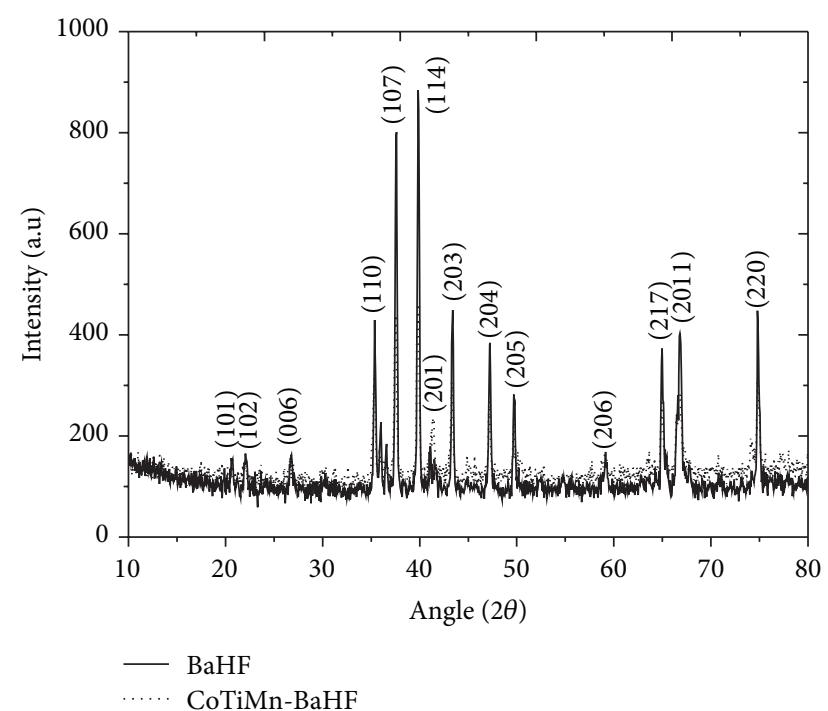

Figure 2: XRD of BaHF and CoTiMn-BaHF.

reduction of particle size of CoTiMn-BaHF may be the main reason of low coercivity. The saturation magnetization (Ms) value for BaHF and CoTiMn-BaHF is $53.89 \mathrm{emu} / \mathrm{gm}$ and remanence $(\mathrm{Mr})$ value is $29.62 \mathrm{emu} / \mathrm{gm}$.

4.4. Permittivity and Permeability Study. The complex permittivity and permeability study represents the magnetic and dielectric properties of the microwave absorber. The real parts

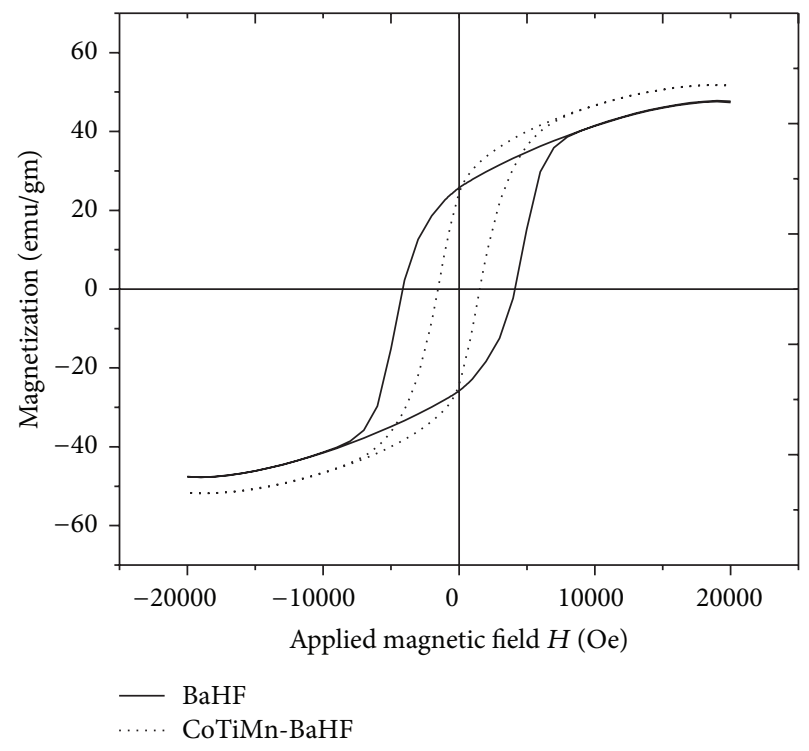

Figure 3: Hysteresis plot of BaHF and CoTiMn-BaHF.

of permittivity and permeability $\left(\varepsilon^{\prime}\right.$ and $\left.\mu^{\prime}\right)$ represent the measure of energy storage capability into the system. The imaginary parts of permittivity and permeability $\left(\varepsilon^{\prime \prime}\right.$ and $\left.\mu^{\prime \prime}\right)$ represent the measure of energy loss capability of the absorber. The real and imaginary component of permeability for multilayer RAM-I and RAM-II were plotted over the range of $8-12 \mathrm{GHz}$ and shown in Figure 4(a). The plot shows real and imaginary component of permeability for both 


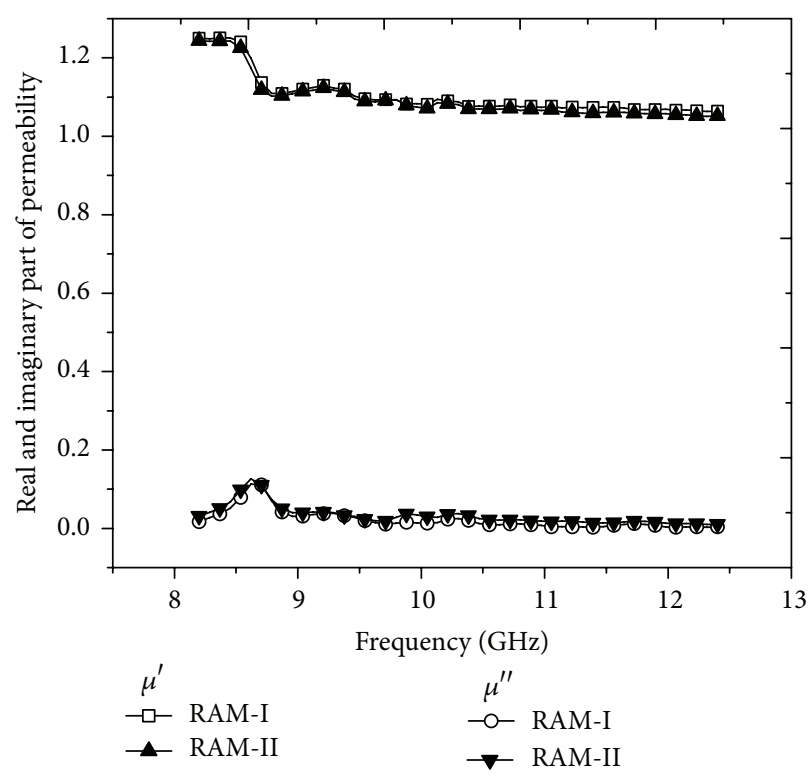

(a)

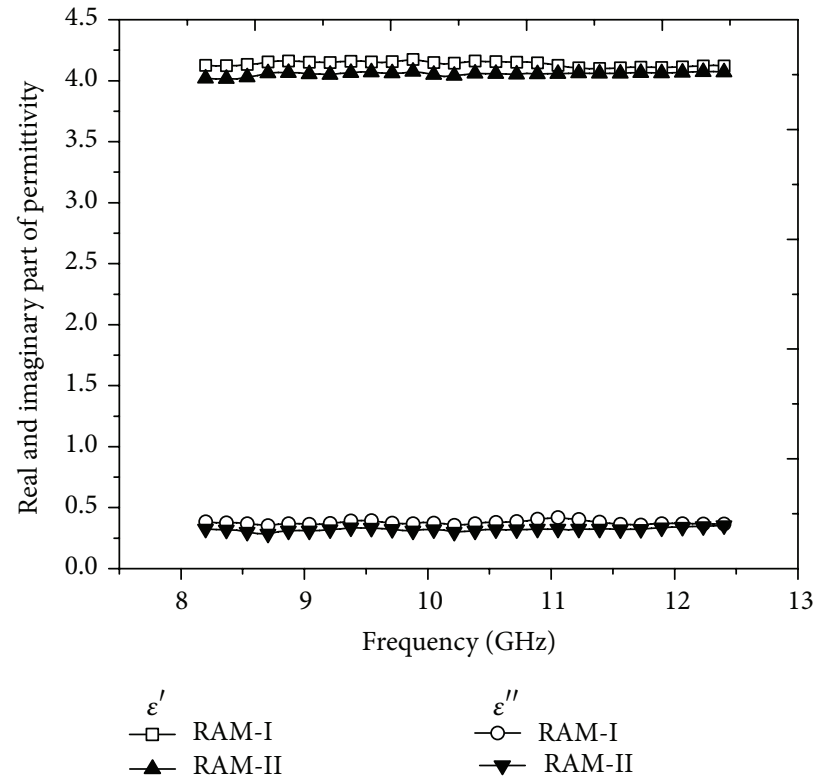

(b)

FIGURE 4: (a) Real and imaginary part of permeability for RAMs (I and II), (b) real and imaginary part of permittivity for RAMs (I and II).

RAM-I and RAM-II which are nearly constant within 9$12 \mathrm{GHz}$ segment. The plot shows that imaginary part of permiability is small and possessed a peak at $8.62 \mathrm{GHz}$, which confirmed the existence of slightly greater magnetic loss mainly because of domain-wall displacement in the magnetic components. Figure 4(b) shows the complex permittivity spectra of the RAM-I and RAM-II. The values of both the real and imaginary parts $\left(\varepsilon^{\prime}\right.$ and $\left.\varepsilon^{\prime \prime}\right)$ of permittivity do not change within the entire frequency range of $8-12 \mathrm{GHz}$. The dielectric loss may occur due to intrinsic electrical dipole moment within double-layer RAMs. In addition to this, dielectric losses can also occur in presence of electromagnetic field due to polarization relaxation.

4.5. Microwave Absorbing Properties. An ideal microwave absorber should meet impedance matching $\left(Z_{\text {in }}=Z_{\mathrm{o}}\right)$ condition [9]. Hexaferrites materials have matching frequency due to magnetic resonance within the X-band region. The absorption condition satisfies where reflection loss value is maximum and condition ideally possible to meet when the materials complex permittivity and permeability values are equal. When intrinsic impedance is greater than unity, $\left|\mu_{r}\right|>\left|\varepsilon_{r}\right|$, maximum attenuation can be achieved if thickness of RAMs is equal to half of wave length $(\lambda / 2)$. If intrinsic impedance of the material is less than unity, $\left|\mu_{r}\right|<\left|\varepsilon_{r}\right|$, then quarter wave length $(\lambda / 4)$ is sufficient to achieve maximum attenuation. For hexaferrite based materials, intrinsic impedance value is less than unity, in X-band frequency range, so maximum attenuation can be achieved if thickness of RAMs will be equal to $\lambda / 4$ or odd multiple of $\lambda / 4$ [1013]. From Figures 5(a) and 5(b), variation of attenuation property with frequency for BaHF and CoTiMn-BaHF based double-layer composite RAMs can be seen. The BaHF based composite (RAM-I) exhibited a reflection loss of $-32 \mathrm{~dB}$ at 10.64 GHz (Figure 5(a)) whereas by doped barium hexaferrite based absorber (RAM-II) it exhibited a maximum reflection loss of $-29.56 \mathrm{~dB}$ at $11.7 \mathrm{GHz}$. It was also observed that $\mathrm{BaHF}$ based composite did not possess a consistence reflection loss below $-20 \mathrm{~dB}$ in the whole range of analysis because of its ferromagnetic resonance at $10.64 \mathrm{GHz}$. However, doped BaHF based double-layer RAMs showed wide bandwidth of absorption in X-band frequency range and the resonance frequency also shifted to $11.7 \mathrm{GHz}$. The better microwave absorption properties of doped barium hexaferrite based RAMs can be attributed to reduction in particle size and coercive force $(\mathrm{Hc})$ as compared to barium hexaferrite (BaHF) based absorber. Figure 5(b) shows the variation of transmission loss versus frequency for RAM-I and RAMII. As expected, transmission loss curves were completely reversed of reflection loss curves.

\section{Conclusion}

Barium hexaferrite with narrow shape and size distribution was successfully synthesized using topotactic sintering method. Doped barium hexaferrite $\left(\mathrm{BaFe}_{10} \mathrm{Co}_{0.8} \mathrm{Ti}_{0.8}\right.$ $\mathrm{Mn}_{0.4} \mathrm{O}_{19}$ ) was prepared by "mixed oxide" approach. Doublelayered RAMs were prepared successfully with both $\mathrm{BaHF}$ and doped BaHF embedded in chloroprene rubber. The maximum reflection loss values were observed as $-32 \mathrm{~dB}$ at $10.64 \mathrm{GHz}$ for $\mathrm{BaHF} / \mathrm{TiO}_{2} / \mathrm{CCB}$ based composite RAMs. The maximum reflection loss value for doped- $\mathrm{BaHF} / \mathrm{TiO}_{2} / \mathrm{CCB}$ based absorber was found to be $-29.56 \mathrm{~dB}$ at $11.7 \mathrm{GHz}$. However, doped BaHF based RAMs showed consistence microwave absorption, which is reflected in reflection loss values, in the whole X-band region. 


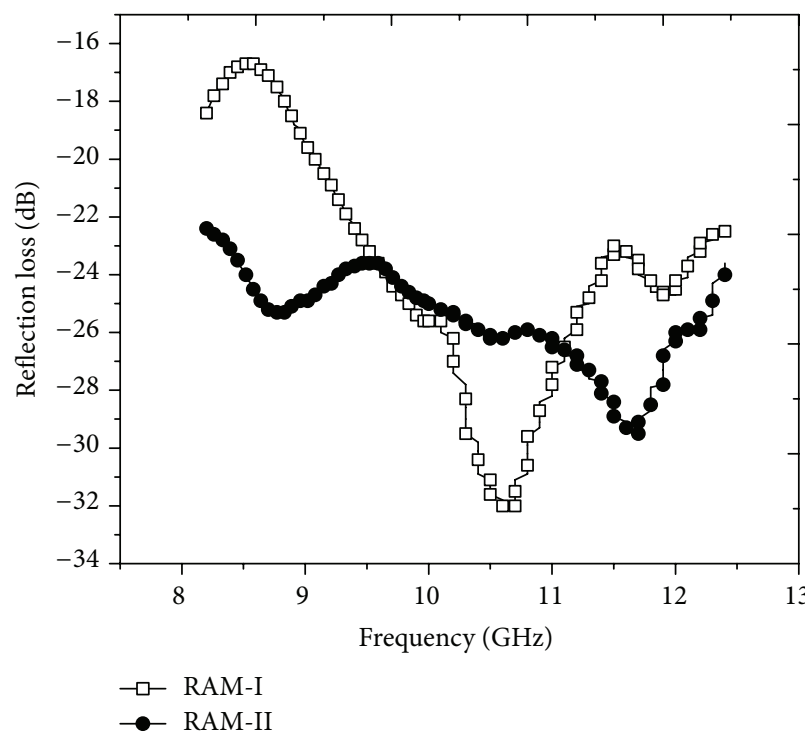

(a)

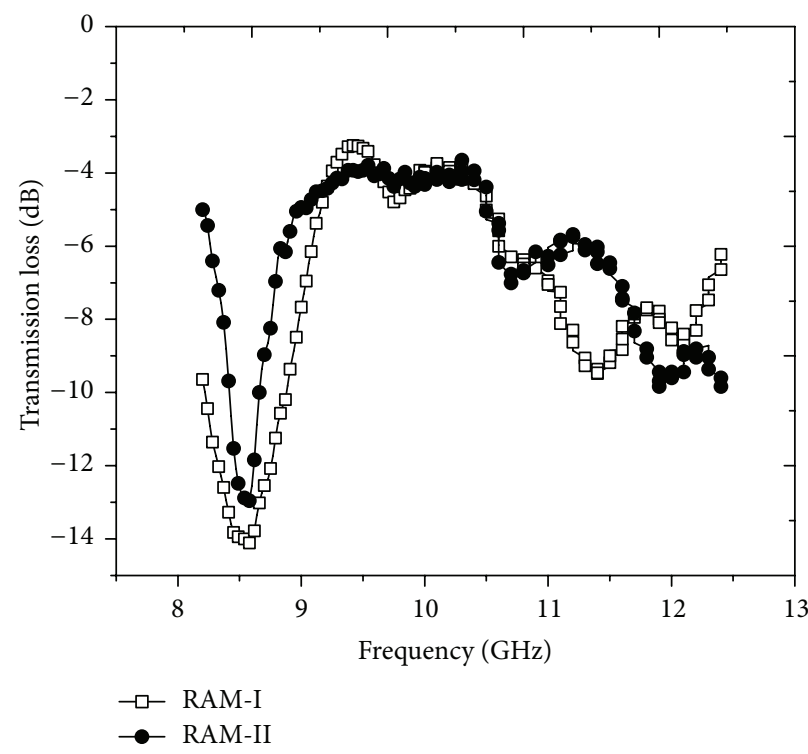

(b)

Figure 5: (a) Reflection loss (dB) versus frequency (GHz). (b) Transmission loss (dB) versus frequency (GHz).

\section{Conflict of Interests}

The authors declare that there is no conflict of interests regarding the publication of this paper.

\section{Acknowledgment}

The authors are grateful for the support from Director of Integrated Test Range (ITR), Defence Research Development Organization (DRDO), Chandipur, India.

\section{References}

[1] A. Ohlan, K. Singh, A. Chandra, and S. K. Dhawan, "Microwave absorption behavior of core-shell structured poly $(3,4$ ethylenedioxy thiophene)-barium ferrite nanocomposites," ACS Applied Materials and Interfaces, vol. 2, no. 3, pp. 927-933, 2010.

[2] R. Sharma, R. C. Agarwala, and V. Agarwala, "Development of radar absorbing nano crystals under thermal irradiation," Journal of Nano Research, no. 2, pp. 91-104, 2008.

[3] S. P. Gairola, V. Verma, A. Singh, L. P. Purohit, and R. K. Kotnala, "Modified composition of barium ferrite to act as a microwave absorber in X-band frequencies," Solid State Communications, vol. 150, no. 3-4, pp. 147-151, 2010.

[4] J. Qiu, Y. Wang, and M. Gu, "Microwave absorption properties of substituted $\mathrm{BaFe}_{12} \mathrm{O}_{19} / \mathrm{TiO}_{2}$ nanocomposite multilayer film," Journal of Materials Science, vol. 42, no. 1, pp. 166-169, 2007.

[5] C. M. A. Lopes, G. G. Peixoto, and M. C. Rezende, "Microwave absorption effectiveness of non woven support impregnated with carbon black," in Proceedings of the SMBO/IEEE MTT-S International Microwave and Optoelectronics Conference (IMOC '03), pp. 771-774, September 2003.

[6] J. L. Gumaste, B. B. Nayak, R. K. Galgali, and B. C. Mohanty, "Barium hexaferrite magnet by topotactic reaction method," Journal of Materials Science, vol. 23, no. 9, pp. 3125-3128, 1988.
[7] R. D. C. Lima, M. S. Pinho, M. L. Gregori, R. C. R. Nunes, and T. Ogasawara, "Effect of double substituted $\mathrm{m}$-barium hexaferrites on microwave absorption properties," Materials Science-Poland, vol. 22, no. 3, pp. 245-252, 2004.

[8] C.-H. Peng, C.-C. Hwang, J. Wan, J.-S. Tsai, and S.-Y. Chen, "Microwave-absorbing characteristics for the composites of thermal-plastic polyurethane (TPU)-bonded NiZn-ferrites prepared by combustion synthesis method," Materials Science and Engineering B: Solid-State Materials for Advanced Technology, vol. 117, no. 1, pp. 27-36, 2005.

[9] S. H. Hosseini and A. Asadina, "Synthesis, characterization, and microwave-absorbing properties of polypyrrole/ $\mathrm{MnFe}_{2} \mathrm{O}_{4}$ nanacomposite," Journal of Nanomaterials, vol. 2012, Article ID 198973, 6 pages, 2012.

[10] A. R. Bueno, M. L. Gregori, and M. C. S. Obrega, "Microwave absorbing of $\mathrm{Ni}_{0.50-x} \mathrm{Zn}_{0.50-x} \mathrm{Mn}_{2 x} \mathrm{Fe}_{2} \mathrm{O}_{4}(\mathrm{Me}=\mathrm{Cu}, \mathrm{Mn}, \mathrm{Mg}$ ) ferrite wax composite in X-band frequencies," Journal of Magnetism and Magnetic Materials, vol. 320, no. 6, pp. 864-870, 2008.

[11] H. S. Al-Jumaili, K. T. Rasoul, and S. N. Al-Rashed, "The effect of $\mathrm{Mn}$ and $\mathrm{Ti}$ substituted barium hexaferrite on the electromagnetic microwave absorber in the X-band range," Journal of Al-Anbar University of Pure Science, vol. 1, no. 2, pp. $62-74,2007$.

[12] H.-M. Xiao, X.-M. Liu, and S.-Y. Fu, "Synthesis, magnetic and microwave absorbing properties of core-shell structured $\mathrm{MnFe}_{2} \mathrm{O}_{4} / \mathrm{TiO}_{2}$ nanocomposites," Composites Science and Technology, vol. 66, no. 13, pp. 2003-2008, 2006.

[13] L. D. C. Folgueras, M. A. Alves, and M. C. Rezende, "Microwave absorbing paints and sheets based on carbonyl iron and polyaniline: Measurement and simulation of their properties," Journal of Aerospace Technology and Management, vol. 2, no. 1, pp. 6370, 2010. 

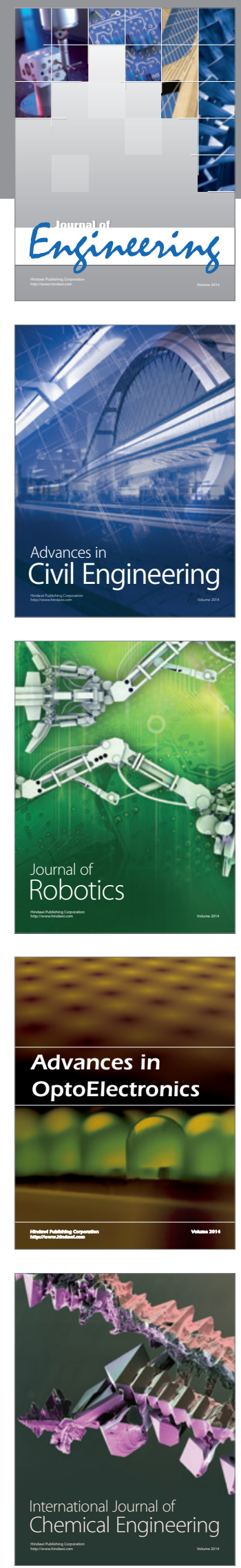

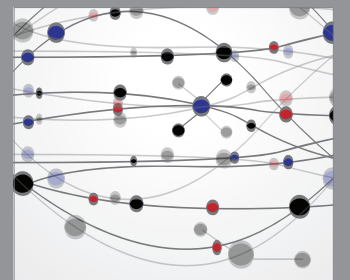

The Scientific World Journal
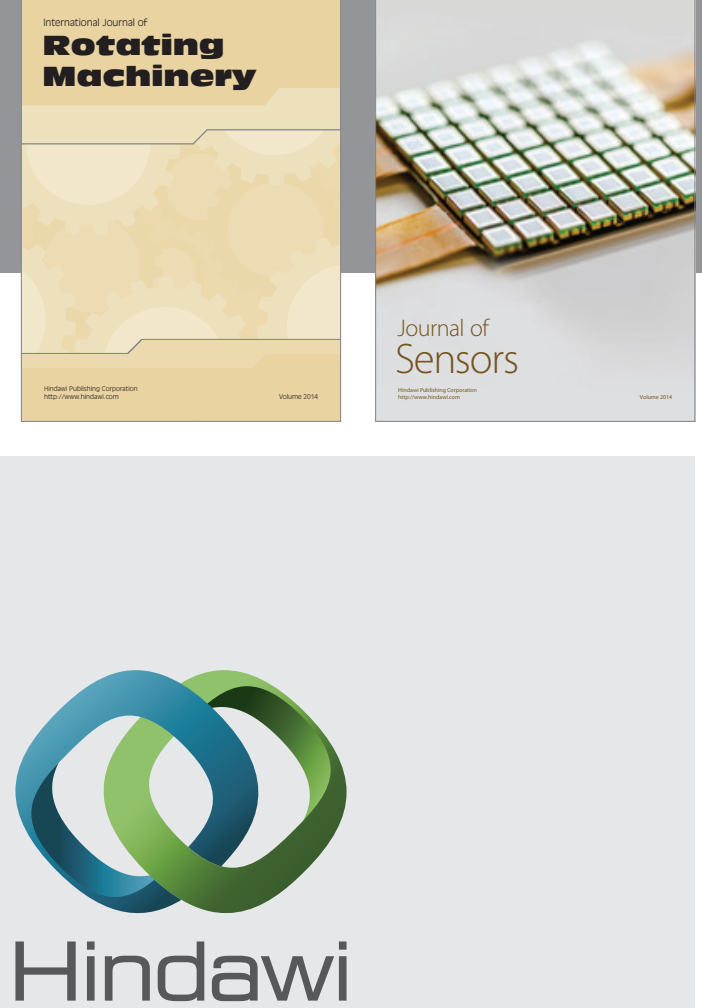

Submit your manuscripts at http://www.hindawi.com
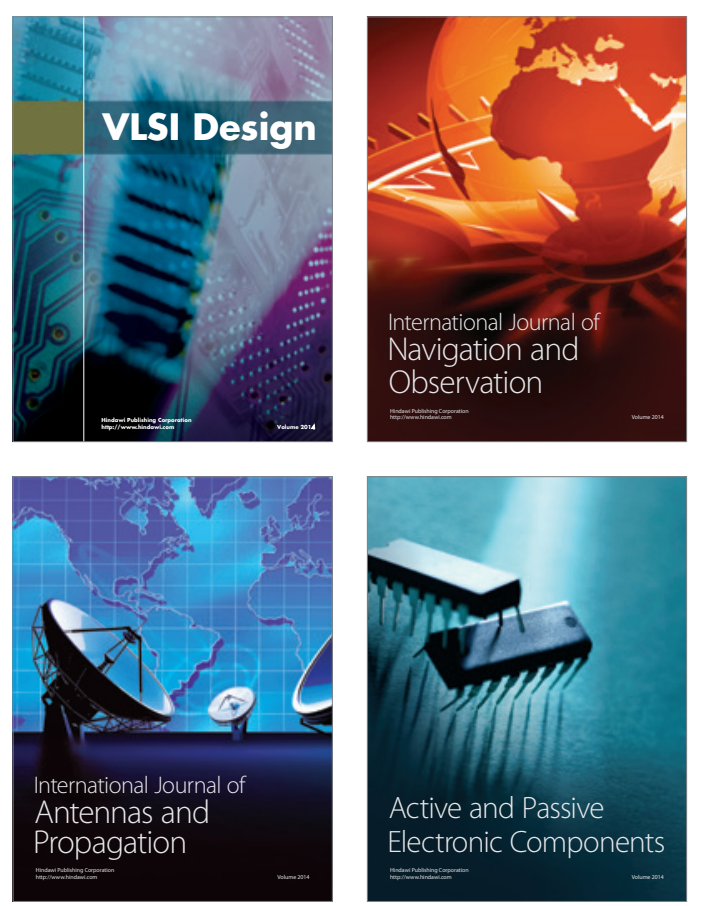
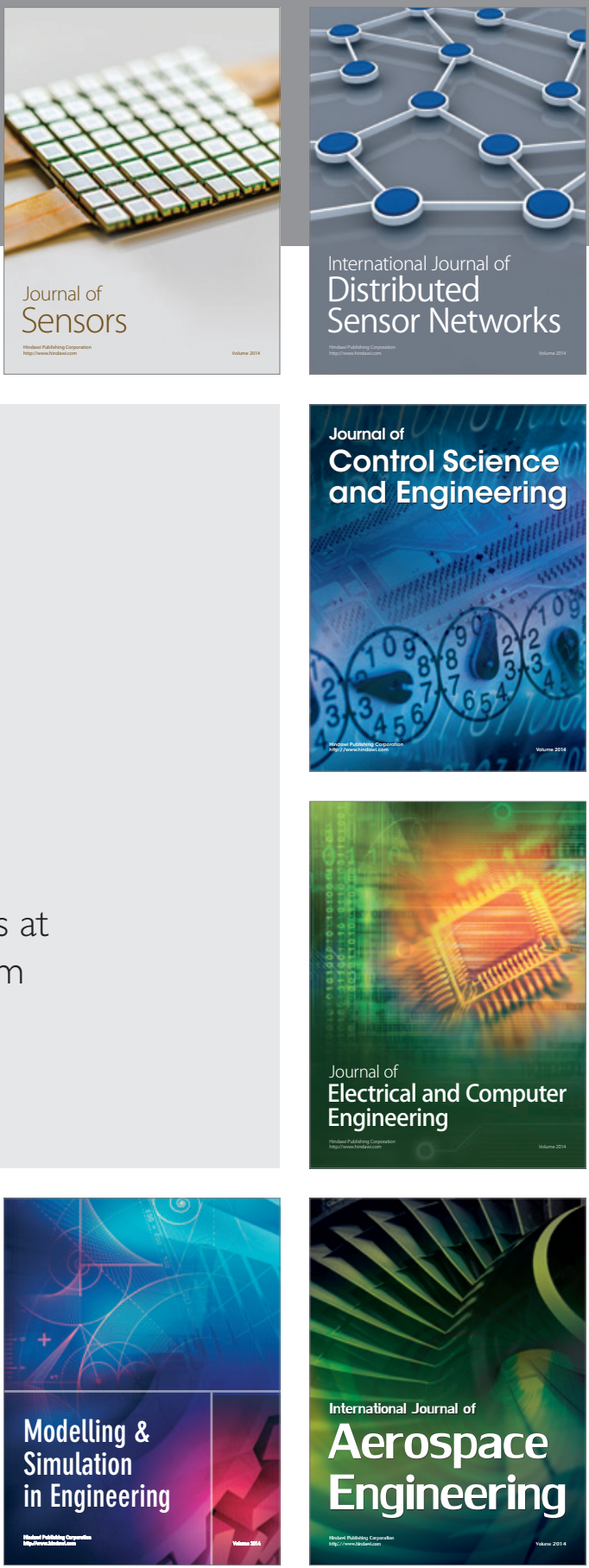

Journal of

Control Science

and Engineering
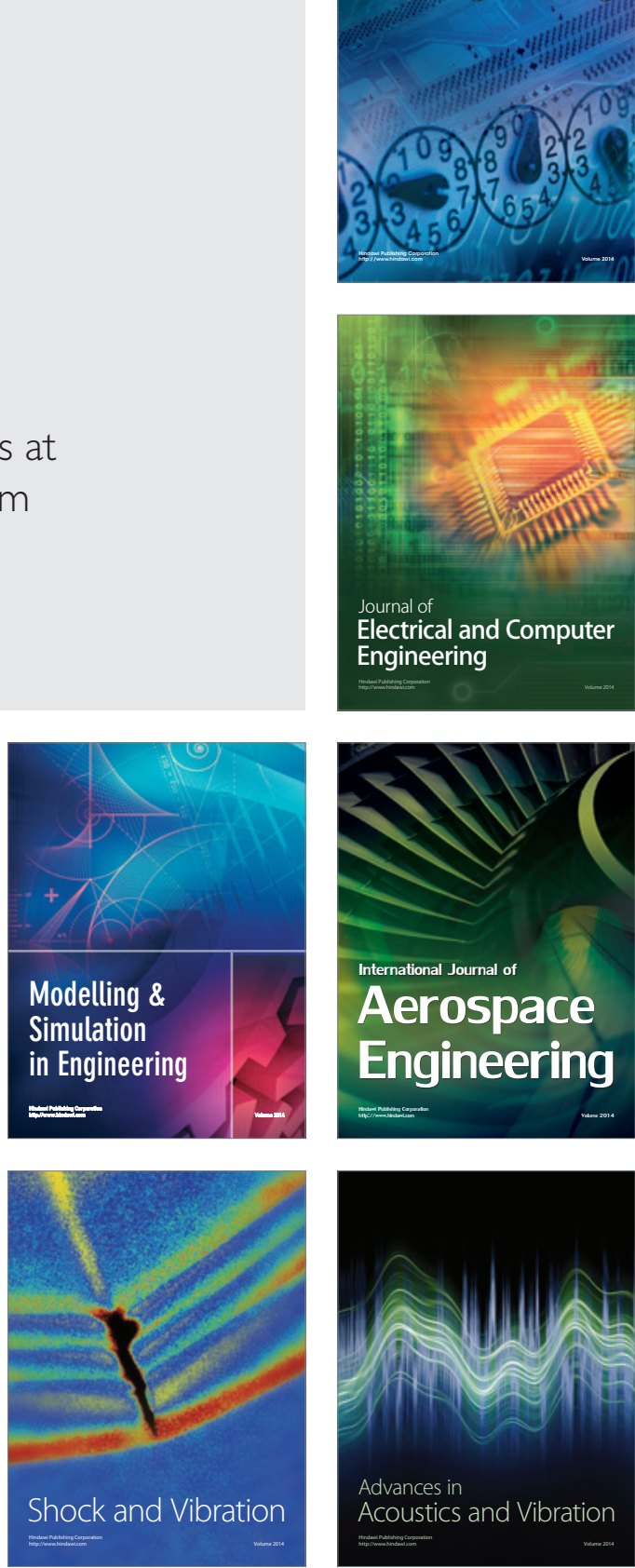